\title{
Filling mode and regularity of vertical centrifugal casting process of titanium alloy in thin-walled cylinder cavity
}

\author{
Qin Xu', Xing Wang', Yong-gang Guo'and *Shi-ping Wü \\ 1. School of Mechanical and Electrical Engineering, Henan University of Technology, Zhengzhou 450001, China \\ 2. School of Materials Science and Engineering, Harbin Institute of Technology, Harbin 150001, China
}

\begin{abstract}
The mold filling process of titanium alloy in a thin-walled cylinder cavity under vertical centrifugal casting process was studied by means of the hydraulic simulation experiments. Results show that the filling mode of the melt in the cylinder cavity varies with casting wall-thickness. When the casting wall-thickness is less than or equal to the thickness of the first layer during the filling process, the melts fill the cavity from the bottom to the top. When the casting wall-thickness is greater than the thickness of the first layer during the filling process, the melts first fill the largest radius parts of the cavity with a certain thickness of the first layer from the bottom to the top of the cavity, and then they fill the cavity from the larger radius part to the smaller radius part. The melt filling ability increases with the increment of the mold rotational speed and the pouring temperature. In another aspect, the melt filling ability rises with the decrement of the melt viscosity, and the melt with the better filling ability is prone to fill the cylinder cavity layer by layer.
\end{abstract}

Key words: titanium alloy; thin-walled casting; vertical centrifugal casting; cylinder-shape cavity; hydraulic experiment; mold filling

CLC numbers: TG146.23 Document code: A Article ID: 1672-6421(2019)02-105-05

$\mathrm{L}^{\mathrm{s}}$ ight weight, near-net shape and integrative production are the developing trends of modern structural castings for the aerospace industry and are the primary objectives in producing high quality castings ${ }^{[1-3]}$. Titanium and its alloys have many good properties, such as low density, high strength, good corrosion resistance and high temperature creep resistance. Furthermore, the specific strength of titanium alloy is far greater than that of steel with high density and aluminum with low strength ${ }^{[4-6]}$. Results show that it is quite considerable to adopt titanium alloy instead of steel and aluminum to cut down the weight of the spacecraft. The other effective way to reduce the weight of the spacecraft is to adopt thin-walled and integrated designed components when producing the aircraft ${ }^{[7-8]}$. Research shows that the weight of the castings can be reduced by $11 \%$ when their wall thickness decreased by $0.5 \mathrm{~mm}$. Therefore,

\section{*Shi-ping Wu}

Male, Ph.D., Professor. Research interests: theory and technology of materials solidification and structure control; numerical simulation of mold filling and solidification.

E-mail: spwu@hit.edu.cn.

Received: 2018-10-08; Accepted: 2019-02-14 thin-walled, complicated, integrated, and precision casting technology has become the main tendency of the titanium alloy components for aviation and aerospace vehicles ${ }^{[9-10]}$.

The filling velocity of the melt can be obviously accelerated during the vertical centrifugal casting process $^{[6,11-12]}$. Therefore, the filling time and the temperature decrement of the melt can be reduced, thus the filling capacity of the liquid melt can be greatly improved ${ }^{[13-14]}$. Thus, vertical centrifugal casting technology has become the main effective method to produce high-quality titanium alloy castings ${ }^{[15-16]}$. Many researchers studied the filling process of titanium alloy during the vertical centrifugal casting process. Suzuki $\mathrm{K}$, et $\mathrm{al}^{[12]}$ found that the velocity of the melt in the vertical centrifugal field is higher at the position with greater radius. Li et al ${ }^{[17]}$ pointed out that the good filling capability of hollow castings with a heavy wall thickness can be obtained by putting the riser at the rotational center or the inside of the hollow. Watanabe $\mathrm{K}$, et al ${ }^{[18]}$ studied the filling ability in the complicated and narrow cavity of several titanium alloys under the vertical centrifugal casting process, and results show that the filling ability of the TC4 and Ti-6Al-Nb alloy is worse 
than that of pure titanium, and the lower filling ability and bigger viscosity of the alloy will lead to misrun of the melt.

For thin-walled titanium alloy castings, the filling mode in the vertical centrifugal casting process is usually different because of their smaller wall thickness. To the best of our knowledge, the filling process of an alloy can directly affect the subsequent solidification process, and is very important to the microstructure evolution and the ultimate service performance of the castings. However, there are still few studies on the filling mode and regularity of thin-walled titanium alloy castings, especially for cylinder-shape castings produced by the vertical centrifugal process. In the present study, the filling mode and its regularity of titanium alloy in the thin-walled cylinder cavity were investigated through hydraulic experiment. The effects of mold rotational speed, viscosity of the melt and the pouring temperature on filling regularity were also studied.

\section{Experimental method}

The schematic of the hydraulic simulation system for the centrifugal casting process is shown in Fig. 1. The hydraulic simulation system is consisted of a HT6000 frequency converter, a centrifugal machine, a cylinder-shape PMMA (polymethyl methacrylate) casting mold, a pouring cup, a high-speed camera and a data processing system. The main components of the centrifugal machine are a three-phase AC motor, a hydraulic coupling and a centrifugal plate. Figure 2(a) shows the prototype of the thin-walled cylinder-shape casting. The outer part of the casting was selected to study the filling mode of TC4 alloy melt in the cylinder-shape cavity. In order to ensure the similarity of fluid dynamics, the height, thickness and diameter of the PMMA casting mold are equal to that of the actual casting. The cylinder-shape PMMA casting mold used to study the filling process of titanium alloy in the cylinder-shape mold under the vertical centrifugal casting process is shown in Fig. 2(b). Figure 3 shows the geometry detail of the PMMA casting mold. The outer diameter of the PMMA casting mold is $300 \mathrm{~mm}$. The gating system of the casting mold is a bottom gating system. Before the experiment was carried out, the PMMA casting mold was fixed on the

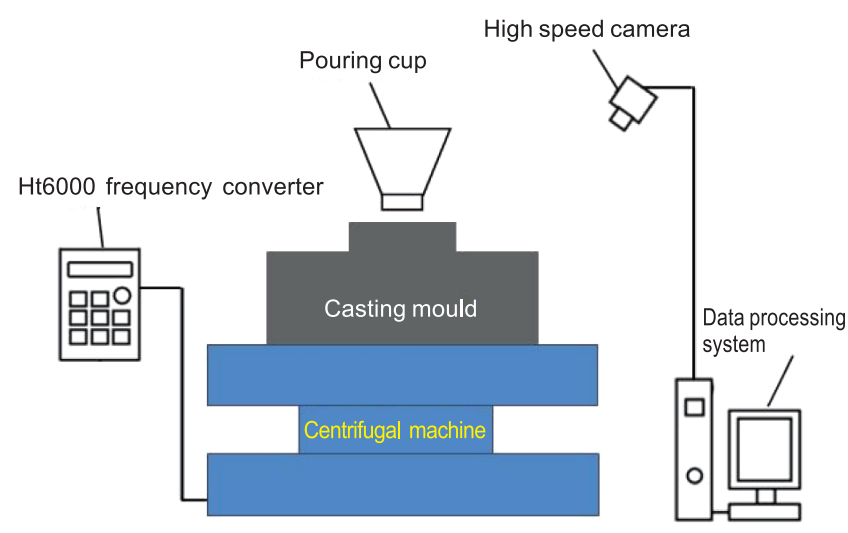

Fig.1: Schematic of setup used for centrifugal casting process
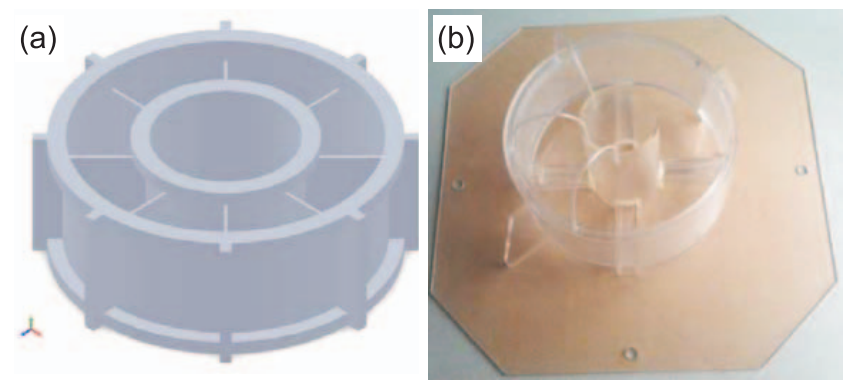

Fig. 2: Prototype and geometry casting mold:

(a) thin-walled cylinder-shape casting prototype; (b) PMMA casting mold

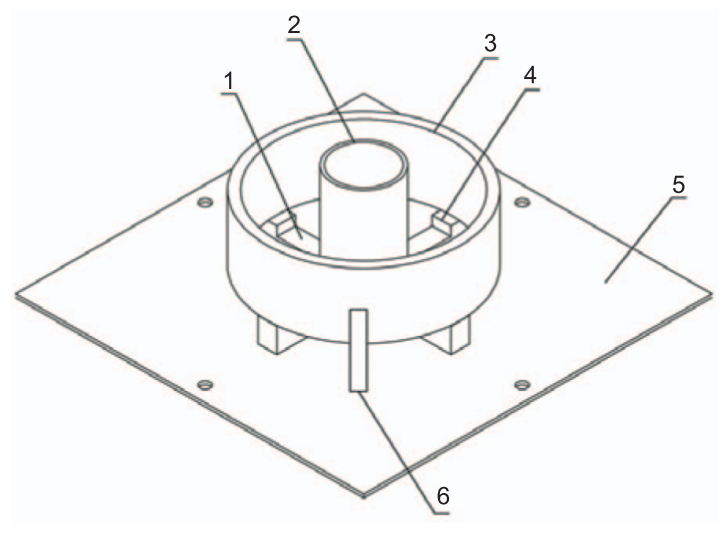

1-runner; 2-sprue; 3-cylinder-shape cavity;

4-inner gates; 5-support plate; 6-base plate

Fig. 3: Geometry detail of casting mold

centrifugal turntable. The rotational speed of the centrifugal turntable ranges from 0 to $1,200 \mathrm{rpm}$. The filling process of the simulated medium in the cylinder-shape cavity was shot by a high-speed camera which could take 1,000 pictures per second.

The PMMA casting mold will soften and deform when the temperature reaches above $50{ }^{\circ} \mathrm{C}$, therefore, the mold filling process cannot be investigated by increasing the temperature of the simulated medium. Thus, the simulated medium made by a mixture of glycerol and water with volume ratios of $1: 1$, 3:1 and 9:1 was prepared and poured at $22{ }^{\circ} \mathrm{C}$ to simulate the effect of the titanium alloy melt temperature and viscosity on the mold filling process in the cylinder-shape cavity ${ }^{[19]}$. The dynamic viscosity of the simulated mediums at $22{ }^{\circ} \mathrm{C}$ are $54 \times 10^{-3} \mathrm{~Pa} \cdot \mathrm{s}, 75 \times 10^{-3} \mathrm{~Pa} \cdot \mathrm{s}$ and $252 \times 10^{-3} \mathrm{~Pa} \cdot \mathrm{s}$, respectively. Hydraulic experiments under different mold rotational speeds of 150, 200 and $300 \mathrm{rpm}$ were carried out to study the effect of the rotational velocity on the filling mode and the regularity of the TC4 alloy melt. Black dyes were added in the simulated medium and the bottom of the mold was lined with a white background to make the captured pictures more clear. Photoshop software was adopted to convert the collected signals of images into corresponding gray values. The higher the gray value, the less the simulated medium at the corresponding location. Contrarily, the lower the gray value, the more the simulated medium at the corresponding location. 


\section{Results and discussion}

\subsection{Filling mode of melt in cylinder-shape cavity}

Figure 4 shows the filling process of the simulated medium in the PMMA casting mold when the mold vertically rotates at $150 \mathrm{rpm}$. The gray values at different positions of the PMMA
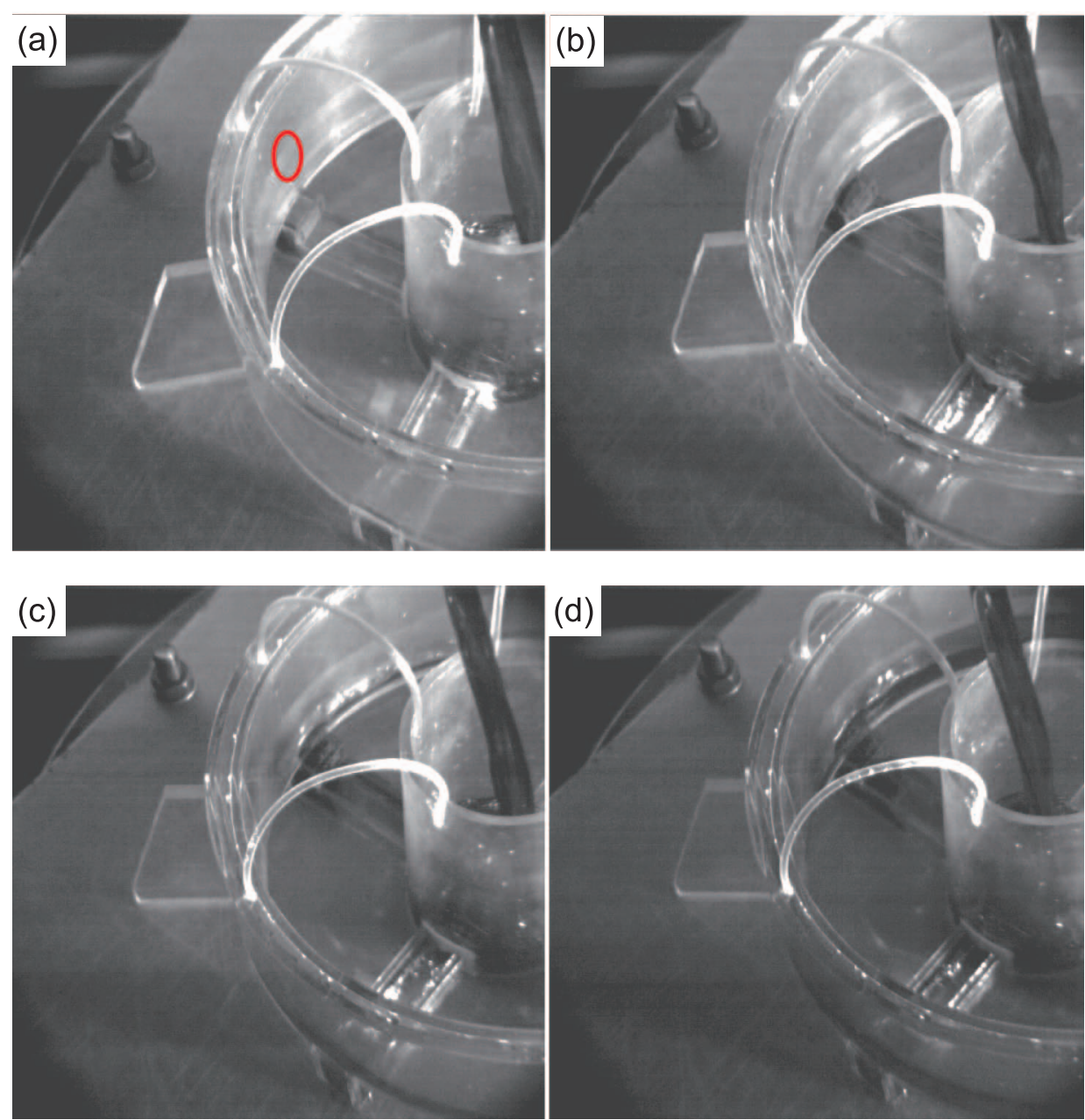

Fig. 4: Filling process in PMMA casting mold $\$ 300$ mm under 150 rpm: (a) 0.265 s; (b) 0.667 s; (c) 1.073 s; (d) 1.484 s

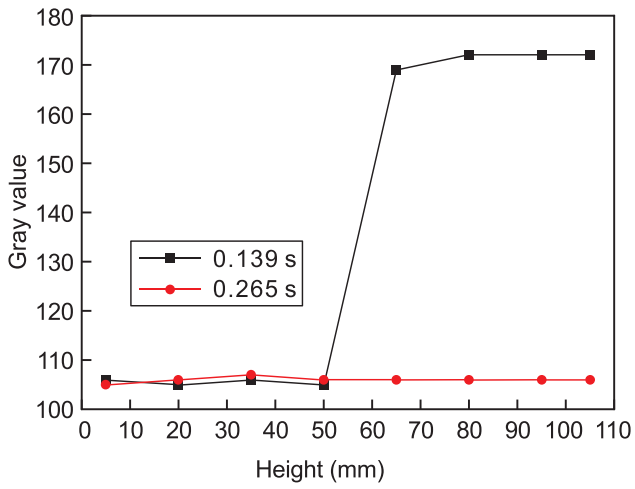

Fig. 5: Gray value in PMMA casting mold at different heights under $150 \mathrm{rpm}$

From the images in Fig. 4, it can be seen that the cavity becomes darker and darker with the filling process of the simulated medium continuing. The gray value at the position casting mold are picked up by Photoshop software. The lower the gray value, the thicker the melt at the corresponding position. Figure 5 shows the gray values of the position at different heights under $150 \mathrm{rpm}$ at $0.139 \mathrm{~s}$ and $0.265 \mathrm{~s}$. The sudden increase of the gray value at $0.139 \mathrm{~s}$ shows that the melt has filled the cavity to the height of $50 \mathrm{~mm}$, and the melt has already filled to the top of the cavity. in the red ellipse shown in Fig. 4(a) at different times of the filling process is selected to study the filling process. The gray values at the selected position at different times shown in Fig. 6 indicate that the gray value of the selected zone is getting lower and lower with the filling process going on. At the beginning of the filling process, the gray value is about 106 . Then, the gray value gradually decreases to about 30 after the filling process is finished, indicating that the thickness of the simulated medium becomes greater and greater with the filling process going on.

Therefore, the simulated medium first fills the largest radius parts of the cavity in a certain thickness from the bottom to the top, and when it reaches the highest of the cavity, it will then fill the cavity from the larger radius parts to the smaller radius parts layer by layer until it fills the whole cavity.

From the hydraulic experiment results of the cylinder-shape cavity, the filling mode of titanium alloy in the cylinder-shape cavity during the vertical centrifugal casting process can be 


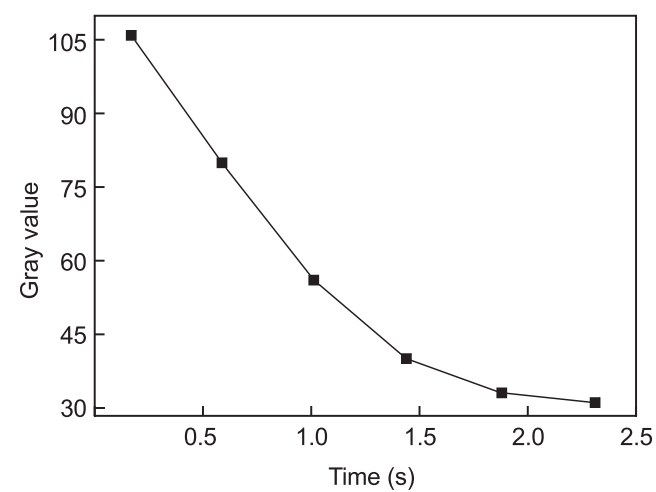

Fig. 6: Gray value in PMMA casting mold of $\$ 300 \mathrm{~mm}$ under $150 \mathrm{rpm}$

divided into the following two stages.

Stage One: the titanium alloy melt first fills the largest radius parts of the cavity with a certain thickness along the axial direction from the bottom to the top [Fig. 7(a)]. At the same time, the melt with this thickness also filled the cavity along the circumference with largest radius opposite to the direction of the rotating casting mold.

Stage Two: the titanium alloy melt reaches the highest end of the cavity and has filled the whole largest radius part of the cavity, then it will fill the cavity from the larger radius parts to the smaller radius parts (that is from the outer radius part to the rotating shaft) layer by layer until it fills the whole cavity [Fig. $7(b)]$. (a)

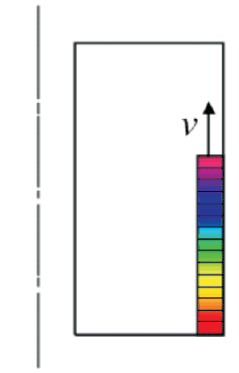

Rotating shaft (b)

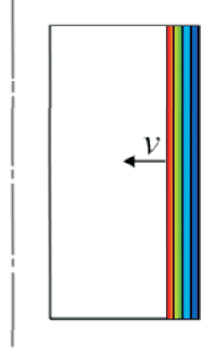

Rotating shaft
Fig.7: Schematic of filling mode in cylinder-shaped casting: (a) first filling stage; (b) second filling stage

Accordingly, if the casting wall thickness is less than or equal to the thickness of the first layer, the titanium alloy melt will fill the whole cavity from the bottom to the top until the whole cavity is full of the melt, that is to say, the filling process contains only Stage One. If the casting wall thickness is more than that of the first layer, the filling process of the melt contains two stages and the melt finally fills the cavity layer by layer in a near perpendicular way from the larger radius parts to the rotating shaft.

\subsection{Effect of mold rotational speed on filling process}

Figure 8 shows the gray values in the red ellipse zone in Fig. 4(a) at different times under the mold rotational speed of 150 , 200 and $300 \mathrm{rpm}$. Results show that the gray values become smaller and smaller whenever the mold rotational speed is high

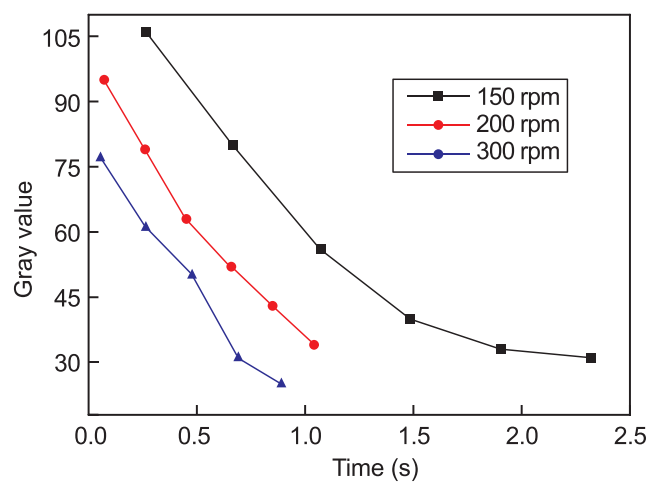

Fig. 8: Gray value under different mold rotational speeds

or low with the filling process going on. On the other aspect, the gray values at the same filling time become smaller with the increment of the casting rotational speed. Therefore, the titanium alloy melt in the vertical centrifugal casting process fills the cavity layer by layer, and the filling ability of the melt in the cylinder-shape cavity is improved by increasing the mold rotational speed. Thus, it tends to be more easy for the melt to fill the cavity layer by layer with increasing the mold rotational speed.

\subsection{Effect of melt viscosity on filling process}

With the same chemical composition, the viscosity of the melt will be lower if its pouring temperature is higher. Thus, researchers can study the effect of the melt pouring temperature on the mold filling process by preparing simulated medium with different viscosities at room temperature. Therefore, simulated medium made by a mixture of glycerol and water with volume ratios of $1: 1,3: 1$ and 9:1 were prepared, and thus, the effect of the melt temperature and melt viscosity on the mold filling process can be studied at room temperature.

Figure 9 shows the gray values in the red ellipse zone marked in Fig. 4(a) during the filling process of simulated medium with volume ratios $1: 1,3: 1$ and $9: 1$ (the dynamic viscosity is $54 \times 10^{-3} \mathrm{~Pa} \cdot \mathrm{s}, 75 \times 10^{-3} \mathrm{~Pa} \cdot \mathrm{s}$ and $252 \times 10^{-3} \mathrm{~Pa} \cdot \mathrm{s}$, respectively) when the mold rotational speed is $150 \mathrm{rpm}$. From the figure it can be known that the gray values during the filling process gradually become smaller and smaller when the ratio of the simulated medium is $1: 1,3: 1$. However, when the ratio of the simulated medium is $9: 1$, the gray value of the red

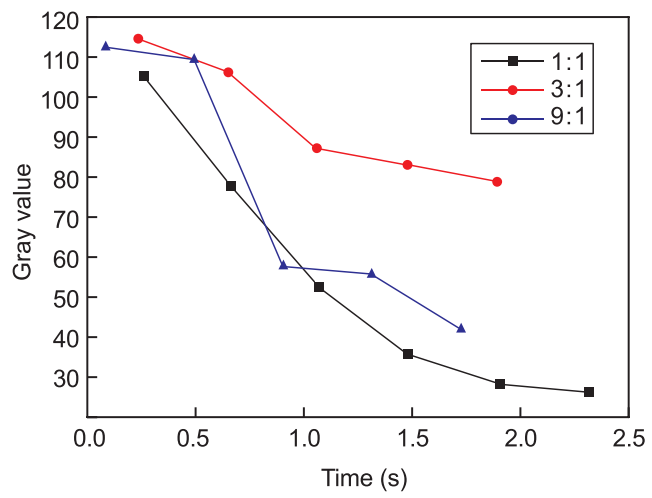

Fig. 9: Gray values with different volume ratios of glycerin/water 
ellipse zone firstly remains almost constantat about 110 , and then has a sharp decrease and falls down to near 60. After that, it has no remarkable changes and maintains a small drop from 60 to 48 . As has been stated above, the dynamic viscosity of the simulated medium $\left(252 \times 10^{-3} \mathrm{~Pa} \cdot \mathrm{s}\right)$ is 4.67 times as that with the ratio of $1: 1\left(54 \times 10^{-3} \mathrm{~Pa} \cdot \mathrm{s}\right)$ and 3.36 times that with a ratio of $3: 1$. The dynamic viscosity is so high that the melt may be in the mushy zone, and the filling capacity of the melt becomes very poor. So the filling state of the melt is quite different with the other melts. Therefore, the filling capacity of the simulated medium will increase with the decrement of the viscosity of the medium, and the medium more easily fills the cavity layer by layer with the decrement of the viscosity of the medium. Consequently, the filling capacity of the titanium alloy melt can be increased by increasing the pouring temperature of the melt according to the relationship of the melt viscosity and the temperature of the melt. And thus, the titanium alloy melt will be more likely to fill the cavity layer by layer with the increment of the temperature of the melt.

\section{Conclusions}

(1) The filling process of the titanium alloy melt in the cylindershape cavity under the vertical centrifugal casting process can be summarized as follows: the melt first fills the largest radius parts of the cavity with a certain thickness along the axial direction from the bottom to the top, then it will fill the cavity from the larger radius parts to the smaller radius parts when the casting wall-thickness is greater than that of the first layer.

(2) The filling mode of the titanium alloy melt under the vertical centrifugal casting process varies with the thickness of the casting wall thickness. If the casting wall-thickness is less than that of the first layer, the melt fills the cavity from the bottom to the top.

(3) The filling ability of the melt in the cylinder-shape cavity is improved by increasing the mold rotational speed and the melt pouring temperature, and the melt with better filling ability tends to more easily fill the cavity layer by layer.

(4) The filling capacity of the simulated medium will increase with the decrement of the viscosity of the medium, and the melt with lower viscosity tends to fill the cylinder-shape cavity layer by layer.

\section{References}

[1] Paul M B. Near net molding methods shape foundries' futures. Modern Casting, 1987, 77(4): 41-46.

[2] Williams J C, Starke E A. Progress in structural materials for aerospace systems. Acta Materialia, 2003, 51(19): 5775-5799.
[3] Jovanovic M. Challenges Ahead: Mitigating Air Transport Carbon Emissions. Polish Journal of Environmental Studies, 2016, 25(5): 1975-1984.

[4] Luo S, Qian M. Microwave processing of titanium and titanium alloys for structural, biomedical and shape memory applications: Current status and challenges. Materials and Manufacturing Processes, 2017, 33(1): 35-49.

[5] Liu C, Sun Q, Liu Y. Experimental and Numerical Study of Progressive Failure of TC4 Titanium Alloy Specimens. Journal of Aeronautical Materials, 2014, 34(6): 84-89. (In Chinese)

[6] Wu S, Xu Q, Zhang J, et al. Solidified structure of thin-walled titanium parts by vertical centrifugal casting. China Foundry, 2011,18(2): 218-222.

[7] Fu Y, Wang H, Zhang C, et al. Numerical simulation and experimental investigation of a thin-wall magnesium alloy casting based on a rapid prototyping core making method. International Journal of Cast Metals Research, 2018, 31(1): 37-46.

[8] Wei $\mathrm{Y}, \mathrm{Hu} \mathrm{K}, \mathrm{Lu} \mathrm{Z}$. Effect of $\mathrm{SiO}_{2}$, concentration in silica sol on interface reaction during titanium alloy investment casting. China Foundry, 2018, 15(1): 23-30.

[9] Abdul-Karem W, Green N, Al-Raheem K F. Vibration-assisted filling capability in thin wall investment casting. International Journal of Advanced Manufacturing Technology, 2012, 61(912): 873-887.

[10] Stroud A W, Ertas A. Development of a rolling finishing system to deliver net shape components from titanium structural extruded shapes. Journal of Manufacturing Processes, 2018, 32: 187-198.

[11] Liang Zuojian, Xu Qingyan, Li Juntao, et al. Research on Numerical Simulation of Investment Casting Process for Gamma Titanium Aluminide Turbocharger. Rare Metal Materials and Engineering, 2003(03): 164-169. (In Chinese)

[12] Suzuki K, Yao M. Simulation of mold filling and solidification during centrifugal precision casting of Ti-6Al-4V alloy. Metals and Materials International, 2004,10(1): 33-38.

[13] Rao A S, Tattimani M S, Rao S S. Understanding Melt Flow Behavior for Al-Si Alloys Processed Through Vertical Centrifugal Casting. Advanced Manufacturing Processes, 2015, 30(11): 1305-1311.

[14] Kim W, Na Y, Hyun Y, et al. A study on fluidity and metal-mold reaction of titanium alloys. Science of Advanced Materials, 2017, 9(11): 1929-1936.

[15] Li C, Wang H, Wu S,et al. Research on Mould Filling and Solidification of Titanium Alloy in Vertical Centrifugal Casting. Rare Metal Materials \& Engineering, 2010, 39(3): 388-392.

[16] Masato D, Sorgato M, Lucchetta G. Prototyping and modeling of the centrifugal casting process for paraffin waxes. Materials \& Manufacturing Processes, 2017, 32(16): 1-7.

[17] Li Xinian. Technology and Application for Irregularly Shaped Castings in Vertical Centrifugal Casting. Special Casting \& Nonferrous Alloys, 2000(5): 30-32. (In Chinese)

[18] Watanabe K, Miyakawa O, Takada Y, et al. Casting behavior of titanium alloys in a centrifugal casting machine. Biomaterials, 2003, 24(10): 1737-1743.

[19] An Geying. Theory of Casting Formation. Beijing: China Machine Press, 1990:15-16. (In Chinese)

This work was financially supported by the National Natural Science Foundation of China (Grant No.51475120) and the Project of Science and Technology of Henan Province of China (2018QNJH25,182102110096). 